Bryant University

Bryant Digital Repository

$10-2014$

\title{
Higher Quality or Lower Price? How Value-Increasing Promotions Affect Retailer Reputation via Perceived Value
}

\author{
Sukki Yoon \\ Bryant University \\ Sangdo Oh \\ Ulsan National Institute of Science \& Technology \\ Sujin Song \\ Korea University Sejong Campus \\ Kyungok K. Kim \\ University of Texas \\ Yeonshin Kim \\ Myongji University
}

Follow this and additional works at: https://digitalcommons.bryant.edu/mark_jou

\section{Recommended Citation \\ Yoon, Sukki; Oh, Sangdo; Song, Sujin; Kim, Kyungok K.; and Kim, Yeonshin, "Higher Quality or Lower Price? How Value-Increasing Promotions Affect Retailer Reputation via Perceived Value" (2014). Marketing Department Journal Articles. Paper 43. \\ https://digitalcommons.bryant.edu/mark_jou/43}

This Article is brought to you for free and open access by the Marketing Faculty Publications and Research at Bryant Digital Repository. It has been accepted for inclusion in Marketing Department Journal Articles by an authorized administrator of Bryant Digital Repository. For more information, please contact dcommons@bryant.edu. 
Higher Quality or Lower Price? How Value-Increasing Promotions Affect Retailer Reputation via Perceived Value.

\author{
Sukki Yoon, Bryant University \\ Sangdo Oh, UNIST \\ Sujin Song, Korea University \\ Kyungok K. Kim, Elon University
}

Yeonshin Kim, Myongji University

Yoon, S., Oh, S., Song, S., Kim, K., \& Kim, Y. (2014). Higher Quality or Lower Price? How Value-Increasing Promotions Affect Retailer Reputation via Perceived Value. Journal of Business Research, 67 (10), 2088-2096. 
Higher Quality or Lower Price? How Value-Increasing Promotions Affect Retailer Reputation via Perceived Value.

\begin{abstract}
Marketers often attempt to increase consumers' perceptions of value by raising the quality or reducing the price of products. Five studies demonstrate that consumers are generally more sensitive to lower-price promotions than to higher-quality promotions as they form their perceptions of retailer reputation (Study 1), that the perceived value mediates this effect (Study 2), that store image (prestigious vs. thrifty) moderates the effect (Study 3), and that perceived price level (Study 4) and quality level (Study 5) independent drive the moderating effect of store image.
\end{abstract}


"A penny saved is a penny earned"

Benjamin Franklin

Researchers have defined perceived value as a psychological trade-off for consumers, their mental trade-off between the gains and sacrifices they expect in transactions (Monroe and Chapman 1987; Monroe 2007, p. 104). A retail shopper considering a purchase is likely to calculate that value $=$ quality/price. Accordingly, marketers can increase buyers' perceptions that they have obtained value by raising product quality while maintaining prices (e.g., J.C. Penny; see Levy and Weitz 2009), or by maintaining product quality while reducing prices (e.g., Saks; see Porter and Helm 2008), or, of course, by changing both (Chaudhuri and Ligas 2009; Grewal, Monroe, and Krishnan 1998). For example, in an attempt to decrease perceived price while holding quality constant, the 2010 IKEA catalog advertises "new lower prices, same great quality." Contrastingly, in an attempt to increase perceived quality while holding prices constant, the 2010 Scion xB automobile offers "improved sound quality [at the] same price," according to recent publicity (Popa 2009).

Although either approach should similarly augment the objective value of a purchase, however, consumers may perceive these two approaches differently. Specifically, we propose that consumers are more sensitive to lower-price promotions (i.e., "lower price with same quality") than to higher-quality promotions (i.e., "higher quality with same price"), although economically both promotions equally increase the total value for shoppers. Heeding Benjamin Franklin's advice, "A penny saved is a penny earned," loss-averse retail consumers may be biased toward price reductions over quality improvements as they judge incremented value. Thus, in this article, we address an important but understudied issue in retailing research: How do these 
two types of value-increasing promotions affect consumers' perceived values of purchases and, consequently, the reputations of the retailers involved?

Furthermore, the current research identifies a condition under which the effect of the lower-price promotion (LPP, hereafter) versus the higher-quality promotion (HQP, hereafter) emerges and disappears. We posit that this price-over-quality effect (the POQ effect, hereafter) will surface when the retailer has a prestigious image and thus gain-focused shoppers are seeking high-quality merchandise. On the other hand, the effect will be dampened when the retailer has a thrifty image and thus loss-focused shoppers are seeking lower-priced merchandise. That is, LPP will have more pronounced superiority over $\mathrm{HQP}$ on value perception and retailer reputation (i.e., the POQ effect) among quality-oriented consumers shopping at a prestigious store, rather than among price-oriented consumers shopping at a thrifty store. Moreover, we dissect the prestigethrift dimension into two distinct constructs - the (perceived) price and quality levels of the retailer - to isolate the effects of these two factors. Consequently, we show that the perceived price level or the perceived quality level of the retailer alone can produce the proposed moderation of the store image on the POQ effect.

This article is organized as follows. The pilot study presents a self-report survey to explore how consumers view their reactions to price reduction versus quality improvement claims. Subsequently, using popular clothing retailer brands, Studies 1 and 2 experimentally test our main idea - the POQ effect - by comparing the two types of value-increasing promotions (i.e., LPP vs. HQP). Next, using department retailer brands, Study 3 addresses whether the strength of the proposed POQ effect depends on the prestigious or thrifty image associated with the retailer. Lastly, because retailers' images, whether prestigious or thrifty, inherently 
encompass the two strongly correlated yet distinct store attributes - the perceived price and quality levels - Studies 4 and 5 use a fictitious retailer brand to experimentally disentangle and separately demonstrate the effects of these two factors.

\section{Perceived Value and Retailer Reputation}

Past research has long recognized retailer reputation as a causal contributor to consumer judgments and behaviors. For example, a good retailer reputation can lead consumers to infer high price and high quality (Dawar and Parker 1994; Dodds, Monroe, and Grewal 1991: Grewal, Munger, Iyer, and Levy 2003; Roggeveen, Bharadwaj, and Hoyer 2007). The literature, however, has yet to consider the factors that shape the retailer's reputation; to the best of our knowledge, no prior work has examined retailer reputation as a dependent variable. To fill this gap, the current research treats retailer reputation as a dependent variable that is positively influenced by the increased value of a purchase. Specifically, we compare the two types of value-increasing promotions - LPP and HQP - and demonstrate that these seemingly similar value-enhancing promotions differentially affect the perceived value of a purchase at a given retailer, which in turn affects the retailer's perceived reputation.

What causes a consumer to perceive that a purchase has value? Monroe (2007, p. 104) defined perceived value as a ratio of perceived benefits (gain) to perceived sacrifice (loss). Grewal, Krishnan, Baker, and Borin (1998) reported findings that are consistent with this definition: perceived price (negatively) and perceived quality (positively) influence perceived value. Similarly, Zeithaml (1988) defined value as "the consumer's overall assessment of the 
utility of a product based on perceptions of what is received and what is given" (p. 14). Then, a practical, tangible summarization of these definitions of value for shoppers in a retail store would be value $=$ quality/price. When confronted by a new price or altered quality, buyers decide whether the difference between the old and new prices/qualities (i.e., changes in the denominator/numerator in the value equation) is significant enough to appreciate the value increment (Monroe 2007). Economically, this would mean that a marketer can increase the perceived value of a purchase by changing either part of the equation: that is, raise the quality while holding the price constant (e.g., "higher quality with the same price") or reduce the price while holding the quality constant (e.g., "lower price with the same quality").

Psychologically, however, quality increases and price decreases may have different impacts on consumer perception of value because "losses loom larger than corresponding gains" (Tversky and Kahneman 1991, p. 1047). Research has robustly shown that consumers tend to prefer avoiding losses to acquiring gains. For example, Kahneman, Knetsch, and Thaler (1990) found that randomly assigned owners of a mug wanted significantly more money to sell it (\$7 average) than randomly assigned buyers would pay to buy it (\$3 average). In the current context of value perception, the price reduction is the diminished loss (from the reference price) and the quality improvement is the augmented gain (from the reference price). Therefore, if consumers tend to avoid losses more intensely than they pursue gains, they should feel price reductions more strongly than they should feel quality improvements. Thus price reductions will more positively affect consumers' perceptions of the retailer's value and reputation.

Research in the pricing literature helps articulate the rationale behind our prediction of the POQ effect. Researchers have shown that price, as a heuristic cue, is more readily observable 
than quality; it is relatively more difficult for consumers to assess the quality of a product and so they must rely on an array of indirect cues (e.g., Nelson 1970; Rao and Monroe 1988).

Consumers learn to distinguish between cues that are highly diagnostic and cues that are not. Price appears to be a more straightforward, highly diagnostic cue than quality (Slovic and Lichtenstein 1983, Herr, Kardes, and Kim 1991; Hoch and Deighton 1989). Furthermore, consumers may not notice quality changes as distinctly as they notice price changes because they must largely evaluate quality depending on their direct consumption experiences, whereas they may assess prices using direct or indirect communications (Monroe 2007, p. 80; Nelson 1970). In addition, researchers have argued that various price-oriented promotions such as coupons, rebates, and regular-versus-sale prices enhance transaction value (i.e., consumers' perceptions that the offer is a "deal") by providing a clear reference point (Monroe and Chapman 1987). No equivalent research, however, has examined whether higher-quality promotions increase perceived value in the same manner as lower-price promotions.

In this regard, Levin and Johnson's (1984) work offer pertinent insight into how these two promotions - LPP and HQP - might differentially shape consumers' perceptions of value increases. The authors provided study participants both price and quality information about ground beef (e.g., \$1.30 and 65\% lean), and later provided them with either price-only (e.g., $\$ 1.50$ ) or quality-only (75\% lean). Study participants estimated the missing information; that is, those who had quality-only information (the quality group) estimated the price of the beef; those who had price-only information (the price group) estimated the quality of the beef. The study showed that participants generally expected constant quality increments when price increased by a fixed amount, and vice versa, but the magnitude of the quality-price tradeoff varied between the price group and the quality group. The amount of value change estimated by the quality 
group were less elastic than the amount of value change estimated by the price group: the value estimates were more varied when they were given price information but not quality information, and less varied when they were given quality information but not price information. Simply put, participants overestimated the value change when they based their estimate on the price change, but they underestimated the value change when they based their estimate on the quality change. Accordingly, we may plausibly assume that consumers respond more strongly to price decreases than to quality increases. Although Levin and Johnson's (1984) findings might indicate that consumers are more sensitive to price changes than to quality changes, no other study has directly compared LPP and HQP. H1, H2, and H3 test this possibility, namely, the POQ effect.

H1: Lower-price promotion (LPP) will more strongly increase retailer reputation than will higher-quality promotion (HQP).

H2: Lower-price promotion (LPP) will more strongly increase perceived shopping value than will higher-quality promotion (HQP).

H3: Perceived value will mediate the relationship between promotion type (LPP vs. HQP) and retailer reputation.

\section{Perceived Store Image: Prestigious or Thrifty?}

Researchers have found that store image is important to consumers in choosing the stores they frequent (Lindquist 1974; Darden, Erdem, and Darden 1983; Zimmer and Golden 1988). Image influences their perceptions of savings, value, and quality (Biswas and Blair 1991; Dodds, Monroe, and Grewal 1991). Grewal, Krishnan, Baker, and Borin (1998) documented a close link 
between consumers' image of a retailer and consumers' perceptions of the quality of products the retailer carries. For example, Grewal et al. (1998) suggested that a prestigious store name such as Nordstrom evokes images of luxurious store environments and high quality merchandise. These findings imply that value-seeking consumers consider both quality and prices, but they will place relative importance on each factor - price and quality - depending on the retail environment. Specifically, consumers shopping at retailers with thrifty images such as Wal-Mart are likely to be price-conscious, implicitly pursuing low prices as their primary goal (Chartrand, Huber, Shive, and Tanner 2008). Consumers shopping at retailers with prestigious images such as Nordstrom are likely to be quality-conscious, implicitly pursuing high quality as their primary goal (Chartrand, Huber, Shive, and Tanner 2008).

Interestingly, we may draw two contrasting yet plausible possibilities regarding the moderating role of prestigious and thrifty store images to strengthen or weaken the POQ effect:

(a) The POQ effect (H1 and H2) may be more pronounced among shoppers at a retailer that has a thrifty image than among shoppers at a retailer that has a prestigious image, or conversely, (b) The effect may be more pronounced among shoppers at a retailer that has a prestigious image than among shoppers at a retailer that has a thrifty image. The former is plausible if consumers are inclined to purchase according to their primary goal only, but not to their secondary goal. Under this static, one-step process model, shoppers continuously adhere to their primary goal, and the POQ effect becomes more observable within the retailer whose image corresponds with their primary shopping goal. That is, according to this model, price-conscious buyers at a thrifty retailer (e.g., Wal-Mart; Chartrand, Huber, Shive, and Tanner 2008) are more likely than qualityconscious buyers at a prestigious store (e.g., Nordstrom; Chartrand, Huber, Shive, and Tanner 
2008), to respond to LPP than to HQP, because both LPP and the thrifty image directly address the shoppers' primary shopping goal of saving money.

The dynamic, two-step process, however, is also tenable: quality-conscious buyers shopping at a prestigious retailer (e.g., Nordstrom) may be more likely than price-conscious buyers shopping at a thrifty retailer (e.g., Wal-Mart) to respond to LPP than to HQP. This occurs because as consumers try to deal with and optimize the trade-off between quality and price aspects of the value equation, they may first opt to select a retailer that addresses their primary goal. Once they have entered the store, they may address their secondary goal. According to this model, as clearly implied by EDLP policies ("everyday low prices"), price-conscious shoppers at thrifty retailers such as Wal-Mart are likely to believe that choosing the thrifty retailer solves the price side of the value equation (i.e., the primary goal). Once they are in the store, they might pursue an additional side to the value equation, quality (i.e., the secondary goal). If this model holds, a thrifty retailer's LPP may not necessarily be more effective than HQP (i.e., the absence of the POQ effect), because value-seeking consumers shopping at the thrifty retailer may become as interested in quality as in price. Likewise, quality-conscious yet value-seeking shoppers at a prestigious retailer like Nordstrom may believe that shopping at a prestigious store guarantees the quality side of the value equation (i.e., the primary goal), so once they are in the store they may focus on finding low-price items (i.e., the secondary goal), so that LPP may have a pronounced effect over the HQP (i.e., the POQ effect). Accordingly, we predict the following contrasting hypotheses: 
H4a: Lower-price versus higher-quality promotion will more strongly affect perceived shopping value and retailer reputation (the POQ effect) when the retailer has a thrifty image than when the retailer has a prestigious image.

H4b: Lower-price versus higher-quality promotion will more strongly affect perceived shopping value and retailer reputation (the POQ effect) when the retailer has a prestigious image than when the retailer has a thrifty image.

\section{Perceived Price-Quality Correlation}

Consumers believe that a positive correlation exists between price and quality: that is, buyers in a retail store tend to use price as an index of product quality and vice versa, assuming the higher the price (quality) the higher the quality (price) of a product or retailer (e.g., Rao and Monroe 1989; Shugan 1984; Zeithaml 1988). This perceived price-quality relationship indicates that the proposed moderating effect of store image on the POQ effect (H4) can be caused by the perceived price level of the given retailer (the high price level of the prestigious retailer and the low price level of the thrifty retailer), or alternatively, it could be caused by the perceived quality level of the given retailer (the high quality level of the prestigious retailer and the low quality level of the thrifty retailer). H5 and H6 address these two accounts respectively.

H5: The perceived price level of the retailer (high- vs. low-price retailer) will drive the two-way interaction between the promotion type (LPP vs. HQP) and the store image (prestigious vs. thrifty images) on value perception (H4). 
H6: The perceived quality level of the retailer (high- vs. low-quality retailer) will drive the two-way interaction between the promotion type (LPP vs. HQP) and the store image (prestigious vs. thrifty images) on value perception (H4).

In Studies 1-5, we experimentally test H1-H6. Before we test our main hypotheses, however, we explore whether consumers indeed realize that they have a POQ bias when they form their value judgments—-that they are relying more heavily on price than on quality. We first address this issue with a pilot study.

\section{Pilot Study}

In the pilot study we seek to explore whether consumers, when forming their value judgments, (a) are aware of the importance of both quality and price and (b) rely on one more than the other. At a private northeastern university, 103 undergraduate freshmen from an introductory marketing course participated in our computer-administered survey in exchange for extra credit. We used two retail settings that college students are familiar with - clothing stores and department stores.

The instruction screen defined value by instructing participants to "please recall that value of (a) product(s) is defined in the following terms: value = quality/price." The first set of questions measured the ease/difficulty of noticing price reductions and quality improvements in

clothing and department stores: "How easy/difficult is it to notice a price reduction of products at a clothing/department store?" and "How easy/difficult is it to notice a quality improvement of 
products at a clothing/department store?" Participants responded on seven-point semantic differential scales, anchored by very easy (1) and very difficult (7).

The second set of questions measured participants' general beliefs about how consumers should versus actually form a value judgment: "When assessing the value of a purchase, to what extent should consumers use the price versus quality information to get the best deal?" and "In reality, when assessing the value of a purchase, to what extent do consumers actually use the price versus quality information?" Participants indicated on seven-point scales, anchored by two extremes: Consumers should (actually tend to) refer to the low price rather than high quality (1); Consumers should (actually tend to) refer to the high quality rather than low price (7).

First, compared to the midpoint of the scale (4), participants reported that they easily notice price reductions $(\mathrm{M}=2.82 ; t(102)=-8.05, p<.01$ for clothing stores; $\mathrm{M}=3.40 ; t(102)=-$ $3.47, p<.01$ for department stores), but they find it more difficult to notice quality improvements $(\mathrm{M}=4.72 ; t(102)=4.43, p<.01$ for clothing stores; $\mathrm{M}=4.98 ; t(102)=6.66, p<$ .01 for department stores).

Similarly, the above-midpoint mean scores indicated that participants generally believe that when consumers assess the value of a purchase, they should refer to high quality rather than low price $(\mathrm{M}=4.73 ; t(102)=5.53, p<.01)$, but that in reality consumers tend to refer to low price rather than high quality $(\mathrm{M}=3.19 ; t(102)=-4.63, p<.01)$.

Pilot study results suggest that when consumers form value judgments, they are aware of the importance of high quality as much as (if not more than) the importance of low price, but perhaps because of loss aversion and difficulties in assessing quality, they tend to discount the 
quality (vs. the price) in their value assessment. In the studies that follow, we investigate whether such belief reflects the true nature of their behavior by experimentally increasing total value by either raising quality or reducing price.

\section{Study 1}

The goal of Study 1 was to test the POQ effect, whether LPP versus HQP differently affect the perceived retailer reputation (H1).

\section{Method}

We recruited 104 undergraduate freshmen from an introductory marketing course at a private northeastern university in exchange for extra credit. The study was administered via computer.

On entering the lab, participants were welcomed and seated in front of a computer monitor that randomly presented one of four scenarios. Participants were asked to imagine a shopping scenario in which they received a catalog from a clothing store (Abercrombie \& Fitch or Hollister $)^{1}$ in the mail. Participants in the lower-price promotion condition imagined receiving the catalog with a cover that advertised "New Lower Prices + Same Great Quality $=$ More Value!" Participants in the higher-quality promotion condition imagined receiving a catalog advertising "New Higher Quality + Same Great Prices = More Value!"

\footnotetext{
${ }^{1}$ We selected these two brands from "The Most Valuable U.S. Retail Brands 2009 Rankings" (Interbrand, 2009) from nine closely ranked clothing retailers. Three judges agreed that Abercrombie \& Fitch and Holister, sibling stores owned by A\&F, share relatively similar images.
} 
Participants were instructed to imagine carefully examining the catalog and finding that many items were, indeed, great values. As the scenario unfolds, they go to the store to buy some items, both large and small. At the checkout counter the sales clerk gives them a comparison table showing that they paid much less than consumers normally pay for the same quality (the LPP condition), or the same price consumers normally pay for much higher quality (the HQP condition).

On the next screen, participants were reminded of the definition of value: "You just remembered that value of (a) product(s) is defined in the following terms: value = quality/price." In the final phase of the scenario, participants were to keep the equation in mind as they evaluated their purchase: "Keeping this equation in mind, you carefully examined the table and thought to yourself, "what a great value!'”

Participants indicated, on seven-point semantic differential scales, the reputation of the store, "please evaluate the store's reputation in the scenario on the following dimension," on three items: bad/good, negative/positive, poor/excellent (Campbell 1999). Participants were then debriefed, thanked, awarded credit, and dismissed.

\section{Results}

The reputation measures (alpha $=.97)$ were submitted to a 2 (Promotion Type: LPP vs. HQP) x 2 (Brand Type: Abercrombie \& Fitch vs. Hollister) factorial ANOVA. As there was neither main effect for Brand Type $(F(1,100)=1.91, p=n . s$.$) nor interaction between$ Promotion Type and Brand Type $(F(1,100)=.02, p=n . s$.$) , we dropped the brand type variable$ from the subsequent analysis. 
As predicted in H1, a significant main effect for Promotion Type supported H1, $(F(1$, $100)=4.18, p<.05)$, indicating that participants in the LPP condition $\left(M_{\mathrm{LPP}}=5.28\right)$ perceived higher retailer reputation than participants in the HQP condition $\left(M_{\mathrm{HQP}}=4.69\right)$.

\section{Discussion}

The results from Study 1 demonstrate the POQ effect, supporting that consumers are more sensitive to price-reducing promotions than quality-enhancing promotions. Study 2 replicates and extends these findings by demonstrating the mediating role of the perceived value between promotion type and retailer reputation.

\section{Study 2}

Study 2 was designed to replicate the results from Study 1 with a different clothing brand and extend the findings to further understand the mechanism driving the relationship between the value-increasing promotion and retailer reputation. As noted earlier, one potential pathway linking these two variables may be via a different perception of value that is caused by the two types of promotions. Accordingly, the objective of Study 2 was to test the mediating role of value perception ( $\mathrm{H} 2$ and $\mathrm{H} 3)$.

\section{Method}

Participants were 54 students who participated for introductory course credit from a private northeastern university. Stimuli, procedures, and measures were identical to those of Study 1 except that we used a different clothing brand (Old Navy) and additionally measured the mediating variable — the perceived value — using three items on a seven-point Likert scale (this 
purchase was a good value for the money; at the price shown this purchase was economical; this purchase was a good buy; Sweeney, Soutar, and Johnson 1999).

\section{Results}

As in Study 1, participants in the LPP condition $\left(M_{\mathrm{LPP}}=5.77\right)$ perceived the higher retailer reputation than participants in the $\mathrm{HQP}$ condition $\left(M_{\mathrm{HQP}}=5.02 ; F(1,52)=5.50, p<.05\right)$.

More importantly, the main objective of Study 2 was to explore the mediating role of the perceived value in the relationship between the type of promotion and retailer reputation. Using Baron and Kenny's (1986) procedure, we conducted a series of regression analyses. In the first equation, retailer reputation $($ alpha $=.96)$ was regressed on dummy-coded promotion type (LPP $=1 ; \mathrm{HQP}=0)$ and the relationship was significant $(\beta=.31, t(52)=2.35, p<.05)$. In the second equation, perceived value (alpha $=.92)$ was regressed on promotion type and the relationship was significant $(\mathrm{H} 2: \beta=.36, t(52)=2.80, p<.01)$. In the third equation, retailer reputation was regressed on perceived value and promotion type; promotion type was no longer significant $(\beta$ $=.06, t(51)=.55, p=n . s$.$) , whereas the influence of perceived value remained significant (\beta$ $=.70, t(51)=6.70, p<.01)$. Sobel's tests confirmed the full mediation (H3: Sobel's $t=2.62 . p$ $<.01)$. These results are shown in Figure 1, indicating that the perceived value of the purchase completely mediated the influence of promotion type on perceived retailer reputation.

Figure 1 here 


\section{Discussion}

The results from Study 2 identify the perceived value as an underlying mechanism that mediates the POQ effect on retailer reputation. Study 3 introduces a boundary condition on the results of Studies 1 and 2.

\section{Study 3}

Study 3 was designed to replicate the findings from Studies 1 and 2 and more importantly, to contrast the competing hypotheses $(\mathrm{H} 4 \mathrm{a}$ and $\mathrm{H} 4 \mathrm{~b})$ to examine whether and how the prestigious versus thrifty store image moderates the POQ effect.

\section{Method}

Participants were 96 students who participated for course credit in an introductory marketing course at a private northeastern university. Stimuli, procedures, and measures were identical to those of Studies 1 and 2 except that in the scenario we used two department store brands, one prestigious and one thrifty: Nordstrom and Wal-Mart. We adopted these two brands from past research (Chartrand, Huber, Shive, and Tanner 2008), which showed that Nordstrom and Wal-Mart activate prestige and thrifty goals, respectively.

Throughout the experiment the brand logo of Nordstrom or Wal-Mart (approximately 2inch diameter) appeared in the background at the lower-right corner of the computer screen.

\section{Results}


To test $\mathrm{H} 3$, the reputation measure (alpha $=.97$ ) was submitted to a 2 (Promotion Type: LPP vs. HQP) x 2 (Store Image: Prestigious vs. Thrifty Image) factorial ANOVA. The promotion type $\mathrm{x}$ store image two-way interaction effect emerged $(F(1,92)=4.09, p<.05)$. As shown in Figure 2, contrasts revealed that participants in the LPP condition $\left(M_{\mathrm{LPP}}=6.32\right)$ perceived higher retailer reputation than did participants in the HQP condition $\left(M_{\mathrm{HQP}}=5.37\right)$ when they read about the prestigious retailer $(F(1,46)=9.25, p<.01)$, but participants in the LPP condition $\left(M_{\mathrm{LPP}}=4.55\right)$ and $\mathrm{HQP}$ condition $\left(M_{\mathrm{HQP}}=4.75\right)$ perceived equal level of retailer reputation when they read about the retailer with a thrifty image $(F(1,46)=.19, p=n . s$.$) .$

Figure 2 here

In addition, the mediation effect from Study 2 was replicated among participants in the prestigious retailer condition $(\mathrm{H} 2)$. When retailer reputation was regressed on promotion type, the relationship was significant, $(\beta=.41, t(46)=3.04, p<.01)$. When perceived value (alpha $=.86)$ was regressed on promotion type, the relationship was also significant, $(\beta=.52, t(46)=$ $4.17, p<.01)$. When retailer reputation was regressed on perceived value and promotion type, promotion type was no longer significant $(\beta=.24, t(45)=1.83, p=n . s$.$) , whereas the influence$ of perceived value remained significant, $(\beta=.43, t(45)=3.23, p<.05)$. This shows that the perceived value of the purchase fully mediated the influence of promotion type on retailer reputation. Sobel's test confirmed the mediation (Sobel's $t(45)=2.14, p<.05$ ).

\section{Discussion}


Study 3 provides further evidence that the perceived value is the underlying mechanism for the retailer reputation, and more importantly, that the store image moderates the POQ effect: participants were more likely to notice the POQ-driven value increment and the increased perceived retailer reputation when the store is associated with a prestigious image (i.e., high quality) rather than when the store has a thrifty image (i.e., low price). These results support the two-step dynamic hypothesis (H4b) but not the one-step static hypothesis (H4a). It appears that consumers may strategically manage the quality aspect of the purchase by selecting a prestigious retailer (Step 1). Once they are in the store, they are more attracted to the price-oriented promotion (Step 2).

However, Study 3 did not distinguish the two important constructs that are highly correlated - the price level and quality level of a retailer (e.g., Rao and Monroe 1989; Shugan 1984; Zeithaml 1988). In other words, the moderating effect of the prestigious versus thrifty store image in Study 3 may have been observed because of the high versus low quality level of Nordstrom versus Wal-Mart or because of the high versus low price of Nordstrom versus WalMart. Studies 4 and 5 are designed to address this issue. That is, Studies 4 and 5 disentangle the effects of these two variables to account for how these two distinct constructs - the perception of price level and quality level of the retailer - independently influence value perception. Using a fictitious store name (Store X), we experimentally manipulate the retailer's price level in Study 4, and the retailer's quality level in Study 5.

\section{Study 4}


Study 4 tested how the perceived price level of a retailer - high versus low - affects perceived value. Consistent with our conceptualization in Study $3(\mathrm{H} 4)$, we predicted that the POQ effect will emerge among participants in the high-price retailer condition, but not among participants in the low-price retailer condition (H5).

\section{Method}

Participants were 72 students who participated for course credit in an introductory marketing course at a private northeastern university. Stimuli, procedures, and measures were identical to those of Study 3 except that we used a fictitious department store brand, Store X, described as a "high-price chain department store" or a "low-price chain department store."

\section{Results}

The perceived value measure $($ alpha $=.89)$ was submitted to a 2 (Promotion Type: LPP vs. HQP) x 2 (Store Image: High-Price vs. Low-Price Image Retailer) factorial ANOVA. The promotion type $\mathrm{x}$ store image two-way interaction effect emerged $(F(1,68)=8.64, p<.01)$. As shown in Figure 3, contrasts revealed that participants in the LPP condition $\left(M_{\mathrm{LPP}}=5.33\right)$ perceived higher value than participants in the HQP condition $\left(M_{\mathrm{HQP}}=3.91\right)$ when they believed that they were shopping in the high-price store $(F(1,36)=4.48, p<.01)$, but participants in the LPP condition $\left(M_{\mathrm{LPP}}=5.05\right)$ and the $\mathrm{HQP}$ condition $\left(M_{\mathrm{HQP}}=5.03\right)$ perceived the equal level of value when they believed that they were shopping in the low-price store $(F(1,32)=.19, p=$ n.s. $)$. Importantly, consistent with our (de)sensitization theorization, these results indicate that when the store has a high-price image, LPP is more likely than HQP to generate consumer responses; however, no such differential responses are likely when the store has a low-price image. 
Figure 3 here

\section{Discussion}

The findings from Study 4 offer partial explanation for the findings from Study 3: the emergence of the POQ effect in the high-price retailer condition and the disappearance of the POQ effect in the low-price retailer condition suggest that the high-price image of a prestigious retailer (e.g., Nordstrom) triggers shoppers to be more likely to react to LPP than HQP, while the low-price image of a thrifty retailer (e.g., Wal-Mart) yields no such difference between LPP and HQP. However, Study 4 does not examine the other side of the prestige versus thrift dimension of the store image: the high- versus low-quality image of the retailer. We address this issue in Study 5 .

\section{Study 5}

In Study 5, we examined how the perceived level of quality associated with a store high- versus low-quality store - affects the perceived value. As in Study 4, we expected that the POQ effect (i.e., that consumers respond more to LPP than to HQP) will emerge among participants in the high-quality store condition, but not among participants in the low-quality store condition.

\section{Method}


Participants were 72 students who participated for course credit in an introductory marketing course at a private northeastern university. Stimuli, procedures, and measures were identical to those of Study 4 except that we described Store $\mathrm{X}$ in the scenario as a "high-quality chain department store" or a "low-quality chain department store."

\section{Results}

The perceived value measure (alpha $=.83$ ) was submitted to a 2 (Promotion Type: LPP vs. HQP) x 2 (Store Image: High-Quality vs. Low-Quality Image) factorial ANOVA. The promotion type $\mathrm{x}$ store image two-way interaction effect emerged $(F(1,65)=4.18, p<.05)$. As shown in Figure 4, contrasts revealed that participants in the LPP condition $\left(M_{\mathrm{LPP}}=5.54\right)$ perceived the higher value than did participants in the HQP condition $\left(M_{\mathrm{HQP}}=4.61\right)$ when they believed that they were shopping in the high-quality store $(F(1,30)=7.26, p<.05)$, but participants in the LPP condition $\left(M_{\mathrm{LPP}}=4.55\right)$ and $\mathrm{HQP}$ condition $\left(M_{\mathrm{HQP}}=4.37\right)$ perceived the equal level of value when they believed that they were shopping in the low-quality store $(F(1$, $35)=.20, p=n . s$. .). As in Study 4 , these findings were again consistent with our (de)sensitization theorization. The results indicated that when the store has a high-quality image, LPP is more likely than HQP to generate consumer responses; however, no such differential responses were found when the store has a low-quality image.

Figure 4 here

\section{Discussion}


The findings from Study 5 provide a supplementary explanation - beyond the findings from Study 4 - for the prestigious versus thrifty image effect from Study 3. Much as the highprice image of a store sensitizes the POQ effect, the high-quality image of a store makes consumers more likely to react to LPP than to HQP.

\section{General Discussion}

This research contributes to the pricing literature by examining the impact of different value-increasing promotions on consumers' actual perceptions of value increment. Specifically, this research is the first to compare the two types of value-enhancing strategies, namely, LPP (lower-price promotion) and HQP (higher-quality promotion). The pilot study shows that consumers (correctly) believe that price change is more noticeable than quality change. The main findings suggest that consumers are generally more sensitive to LPP than to HQP in their perception of retailer reputation (Study 1) and that perceived value (viz., the POQ: the priceover-quality effect) mediates these effects (Study 2). Furthermore, we find that the retailer associated with a prestigious (thrifty) image strengthens (dampens) the POQ effect (Study 3),

driven by both the perceived price level (Study 4) and the perceived quality level (Study 5) of the retailer.

This moderation effect is in line with our two-step process conceptualization: it appears that quality-conscious yet value-prone shoppers first deal with the purchase quality (i.e., the gain side of the value equation) by selecting a prestigious retailer, and next focus on the purchase price (i.e., the loss side of the value equation) while they are in the store. As a result, those who 
shop at a prestigious store, compared with those who shop at a thrifty store, respond more to the price- (vs. quality-) oriented promotion. It seems that when consumers are shopping in prestigious stores featuring high-quality merchandise, they tend to believe that the quality side of the value has been automatically fulfilled. The shopper then shifts concerns from quality to price and becomes more receptive to LPP than HQP.

Our findings can help retail managers decide whether and when to execute price- versus quality-oriented value-enhancing promotions. For example, contrary to the conventional belief that LPP may potentially harm the upscale image of prestigious retailers, the present findings provide a rationale for prestigious retailers to aggressively pursue more price-oriented in-store promotions. As our results suggest, LPP is likely to enhance the perceived retailer reputation among value-prone consumers. The findings do not suggest, however, that upscale retailers should embrace the lower-price approach on every front line of marketing communications such as advertising. As our two-step theory predicts, when quality-conscious consumers are selecting stores to frequent, they are likely to rely on a store's high-quality image. At that time, LPP via mass advertising might dilute the retailer's upscale image.

For a similar reason, thrifty retailers might not benefit as much from in-store LPP as HQP, as shoppers, once they are in the store, might no longer focus on prices. This implication is consistent with the EDLP philosophy - by offering "everyday low prices," the retailer frees customers from price concerns. For this reason, LPP executed by a low-price retailer would not necessarily be more effective than HQP, which suggests that managers at thrifty retailers may cautiously consider quality-oriented in-store promotions. Conceptually, our results suggest that, 
in general, retail managers who are planning value-increasing promotions should focus on their weakness rather than on their strength.

This paper also attempts to experimentally disentangle the effects of the two related attributes of the store image - price and quality levels - and demonstrates that price or quality alone can moderate the effect of the store image on value perception. These findings offer additional evidence that even when the retailer has no particular holistic image, consumers may use available cues - price and quality level - to infer store characteristics. Our data show that high (low) price or high (low) quality alone can trigger the prestigious (thrifty) image effects, suggesting that when consumers are in the value-prone mode they tend to equate high- (low-) price or high- (low-) quality of the store with a prestigious (thrifty) image. 


\section{Figures}

Figure 1. Mediation by Perceived Value

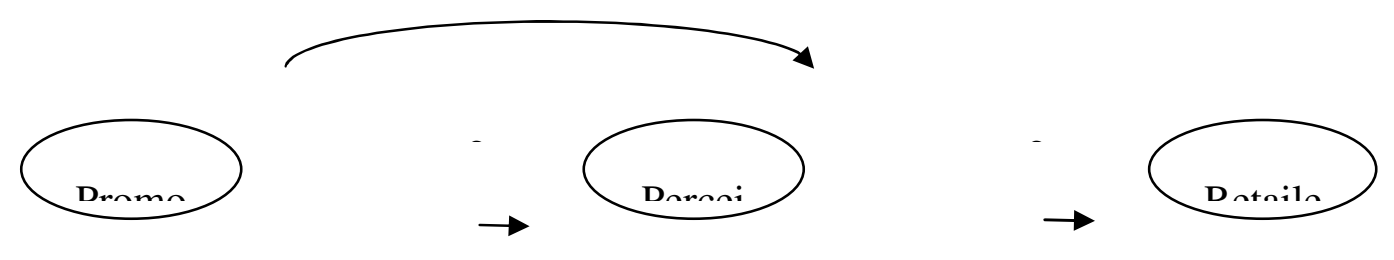

Figure 2. Moderation by Prestigious versus Thrifty Store image (Nordstrom vs. Wal-Mart)

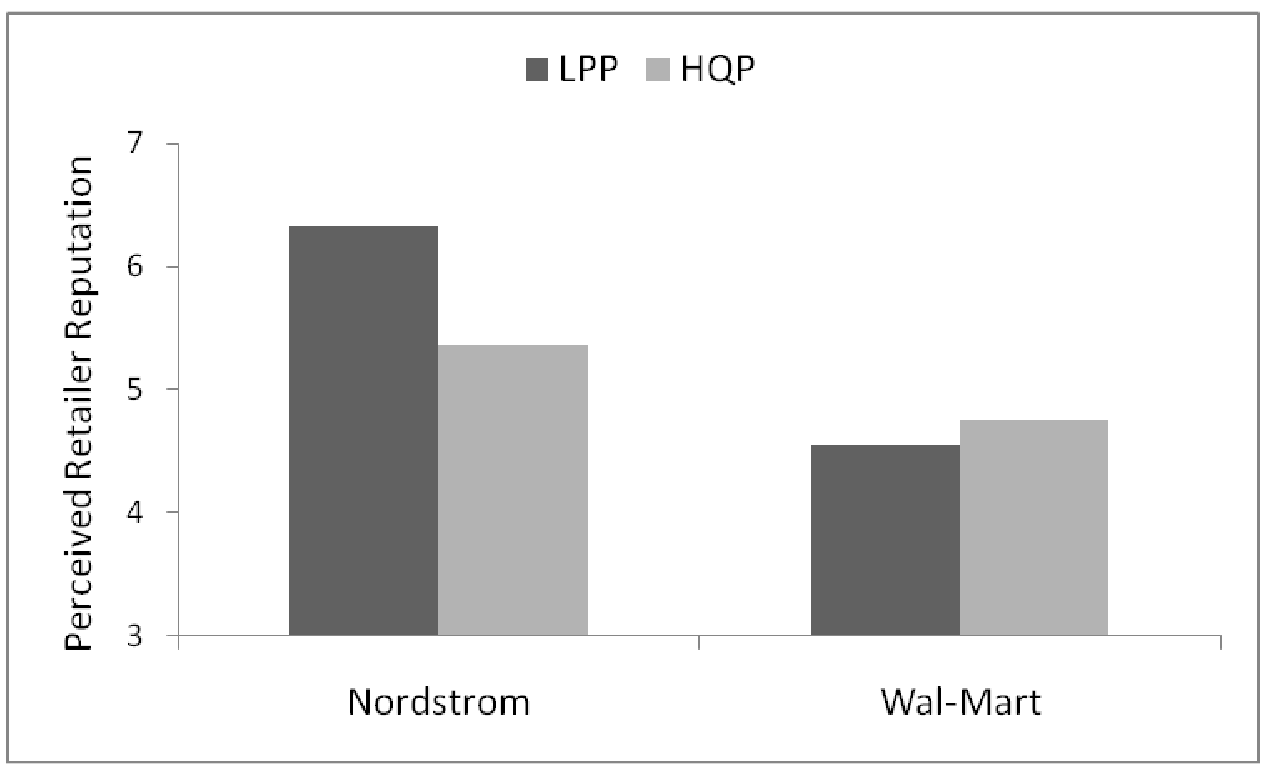


Figure 3. Moderation by High- versus Low-Price Level Retailer

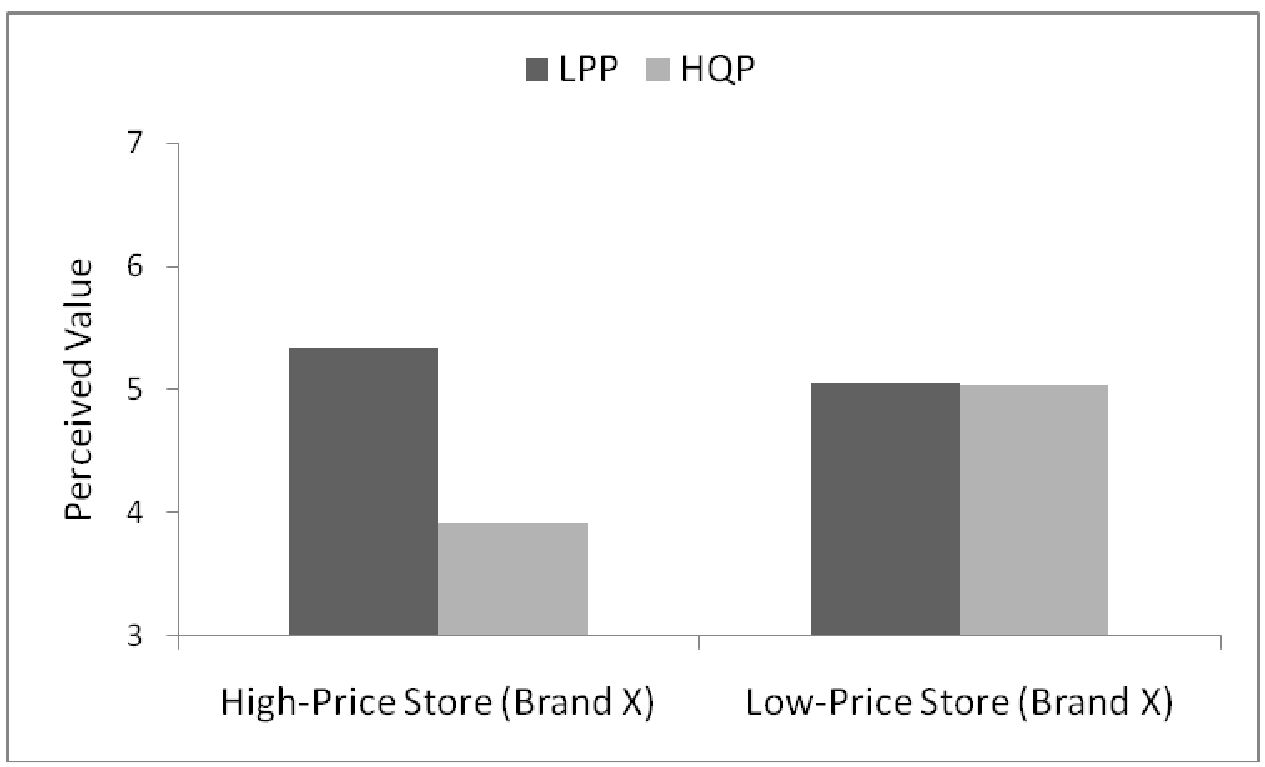

Figure 4. Moderation by High- versus Low-Quality Level Retailer

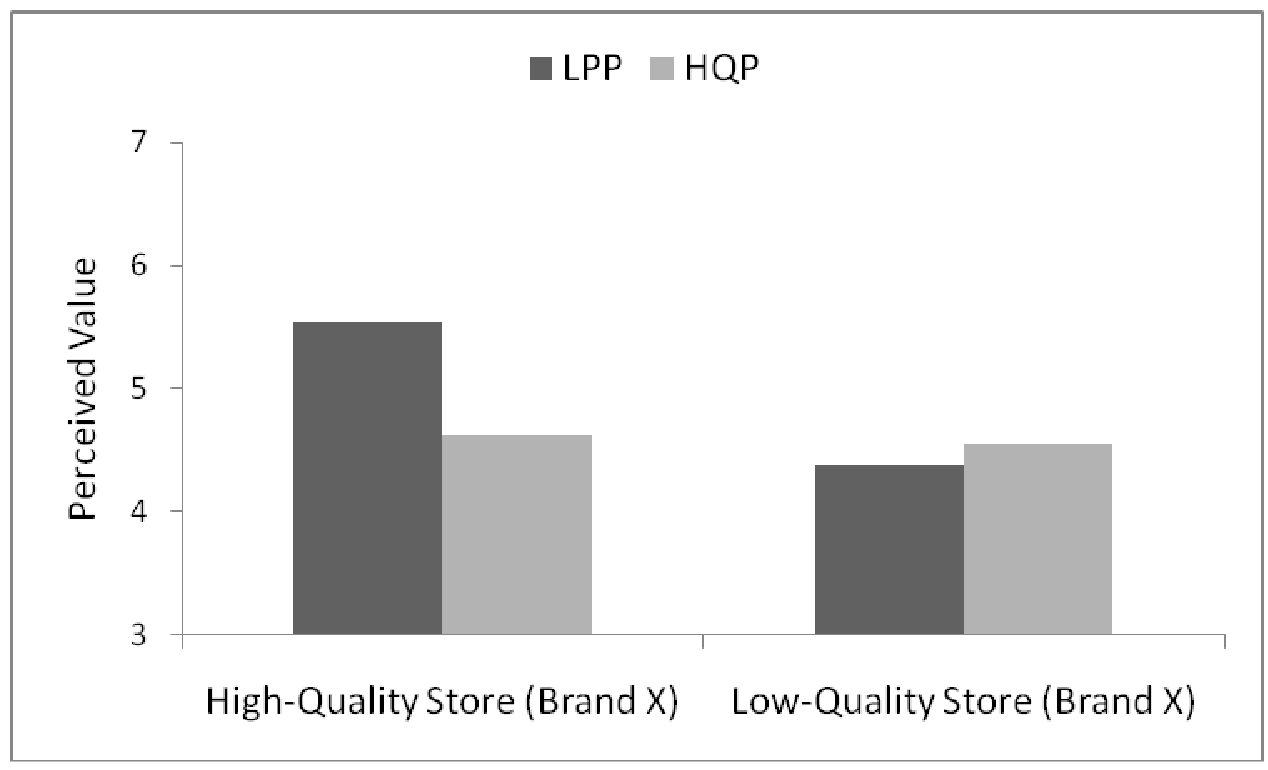




\section{References}

Biswas, Abhijit and Edward Blair (1991), "Contextual Effects of Reference Prices in Retail Advertisements," Journal of Marketing, 55 (July), 1-12.

Campbell, Margaret C. (1999), "Perceptions of Price Unfairness: Antecedents and Consequences," Journal of Marketing Research, 36 (May), 187-199.

Chaudhuri, Arjun and Mark Ligas (2009), "Consequences of Value in Retail Markets," Journal of Retailing, 85 (3), 406-419.

Chartrand, Tanya, Joel Huber, Baba Shive and Robin Tanner (2008), "Nonconscious Goals and Consumer Choice," Journal of Consumer Research, 35 (2), 189-201.

Darden, William, Orban Erdem and Donna Darden (1983), "A Comparison and Test of Three Causal Models of Patronage Intentions," in Patronage Behavior and Retail Management, William Darden and Robert Lusch, eds. New York, NY: Elsevier, 20-43.

Dawar, Niraj and Philip Parket (1994), "Marketing Universals: The Use of Brand Name, Price, Physical Appearance, and Retailers' Reputation as Signals of Product Quality," Journal of Marketing, Vol. 58 (2), 81-95.

Dodds, William, Kent Monroe and Dhruv Grewal (1991), "Effects of Price, Brand, and Store Information on Buyers' Product Evaluations," Journal of Marketing Research, 28(August), $307-319$.

Grewal, Dhruv, R. Krishnan, Julie Baker, and Norm Borin (1998), “The Effect of Store Name, Brand Name and Price Discounts on Consumers' Evaluations and Purchase Intentions," Journal of Retailing, 74 (3), 331-352. 
Grewal, Dhruv, Kent B. Monroe and R. Krishnan (1998), “The Effects of Price-Comparison Advertising on Buyers' Perceptions of Acquisition Value, Transaction Value, and Behavioral Intentions," Journal of Marketing, 62 (2), 46-59

Grewal, Dhruv, Jeanne L. Munger, Gopalkrishnana R. Iyer and Michael Levy (2003), “The Influence of Internet-Retailing Factors on Price Expectations," Psychology and Marketing, $20(6), 477-493$

Herr, Paul, Frank Kardes and John Kim (1991), "Effects of Word-of-Mouth and ProductAttribute Information on Persuasion: An Accessibility-Diagnosticity Perspective," Journal of Consumer Research, 17 (March), 454-462.

Hoch, Stephen and John Deighton (1989), "Managing What Consumers Learn From Experience," Journal of Marketing, 53 (April), 1-20.

Interbrand (2009), “The Most Valuable U.S. Retail Brands 2009 Rankings,”. Available at http://www.interbrand.com/branding_feature.aspx? bfeatureid=8\&langid=1000 (Accessed July 1, 2010)

Kahneman, Daniel, Jack Knetsch and Richard Thaler (1991), "The Endowment Effect, Loss Aversion, and Status Quo Bias," Journal of Economic Perspectives, 5 (1), 193-206.

Levin, Irwin and Richard Johnson (1984), “Estimating Price-Quality Tradeoffs Using Comparative Judgments," Journal of Consumer Research, 11 (June), 593-600.

Lindquist, Jay (1974), “Meaning of Image,” Journal of Retailing, 50 (Winter), 29-38.

Levy, Michael and Barton Weitz (2009), "Retailing Management,” New York, NY: McGraw Hill. 
Monroe, Kent (2007), "Pricing: Making Profitable Decisions," Lawrence Erlbaum, New York, NY: McGraw Hill.

Monroe, Kent B. and Joseph D. Chapman (1987), "Framing Effects on Buyers' Subjective Product Evaluations," in Advances in Consumer Research. Melanie Wallendorf and Paul Anderson, eds. Provo: Association for Consumer Research, 193-197.

Nelson, Philip (1970), "Information and Consumer Behavior," Journal of Political Economy, 78 (2), 311-329.

Popa, Bogdan (2009), “2010 Scion xB: Same Price, Improved Sound Quality,”. Available at http://www.autoevolution.com/news/2010-scion-xb-same-price-improved-sound-quality-

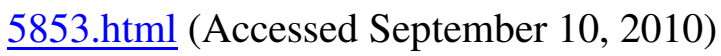

Porter, Jane and Burt Helm (2008), "Doing Whatever Gets Them in the Door," Business Week, June 30, p. 60 .

Rao, Akshay and Kent Monroe (1988), “The Moderating Effect of Prior Knowledge on Cue Utilization in Product Evaluations," Journal of Consumer Research, 15 (September), 253264. and (1989), “The Effect of Price, Brand Name, and Store Name on

Buyers' Perceptions of Product Quality: An Integrative Review" Journal of Marketing Research, $26(3), 351-357$

Roggeveen, Anne, Neeraj Bharadwaj and Wayne Hoyer (2007), "How Call Center Location Impacts Expectations of Service from Reputable versus. Lesser Known Firms," Journal of Retailing, 83 (4), 403-410. 
Shugan, Steven (1984), "Price-Quality Relationships," in Advances in Consumer Research. Vol 11, Thomas Kinnear, eds. Ann Arbor: Association for Consumer Research, 627-632

Slovic, Paul and Sarah Lichtenstein (1983), "Preference Reversals: A Broader Perspective," American Economic Review, 73 (4), 596-605.

Sweeney, Jillian, Geoffrey Soutar and Lester Johnson (1999), "The Role of Perceived Risk in the Quality-Value Relationship: A Study in a Retail Environment," Journal of Retailing, 75 (1), 77-105.

Tversky, Amos and Daniel Kahneman (1991), "Loss Aversion in Riskless Choice: A ReferenceDependent Model," Quarterly Journal of Economics, 106 (4), 1039-1061.

Zeithaml, Valarie (1988), “Consumer Perceptions of Price, Quality, and Value: A Means-End Model and Synthesis of Evidence," Journal of Marketing, 52 (July), 2-22.

Zimmer, Mary and Linda Golden (1988), "Impressions of Retail Stores: A Content Analysis of Consumer Images,” Journal of Retailing, 64 (Fall), 265-293. 